and strychnine and to await events naturally. This he did, but the product of conception en masse was not expelled until Nov. 2nd, 1905. The embryo had evidently perished early in January, when it was about ten weeks old, but gestation was only terminated towards the middle of the thirteenth month, i.e., on the 379 th day after the cessation of the last menstruation.

Gordon-square, W.c.

\section{TWO CASES OF ANENCEPHALY.}

\section{BY R. Brooks Popham, M.R.C.P. Edin., L.R.O.P. Lond.}

SoMr time since I attended two consecutive cases of labour within 24 hours, the result in each of them being a birth of this type of monstrosity. As a contribution to the general question of the frequency of foetus anencephalus the details may be worthy of record. The following are extracts from my case-book and the clinical history seems either coincidental or, in one or more points, significant.

In the first case the mother was 35 years of age, was in her second pregnancy, and was delivered in the eighth month. Her first child was hydrocephalic and the present one was anencephalic. Hydramnios and uterine inertia were present. The father had children by a previous wife, one markedly hydrocephalic and another with spina bifida. In the second case the mother was 32 years of age, had three healthy children, and was delivered in the eighth month. Uterine inertia and excessive bydramnios were noted. The part which presented was the face. The mother had been frightened in early pregnancy by seeing a child with "a very large bead" at Great Ormond-street Hospital.

In both the above cases the births were premature, hydramnios was present, and both mothers were over 30 years of age. The foetuses had forms of talipes. The family history in the first case is significant, for it would seem as though the father had a special tendency to generate children with nervous defects. How often do we notice this tendency-apart from the subject of anencephaly - to beget children with abnormalities of the cerebro-spinal systems so marked as to be of etiological import, and I should be pleased to know if the apparent tendency in the case quoted equally constitutes a bearing on the fotus anencephalus.

Argyle-road, West Ealing, W.

\section{A CASE OF IDIOSYNCRASY OF THE SKIN IN REGARD} TO MERCURIC CHLORIDE.

By Rocco Bellantont, M.D.

THe patient whose case is here described was an Italian girl, 20 years old, very robust, and of a healthy constitution. She suffered from a subaxillary abscess which $I$ incised. For the disinfection of the skin $I$ used, in accordance with my constant practice, washing with a solution of mercuric chloride of strength $I$ in 1000 and $I$ employed less than one litre of the solution. The local treatment was very simple, sterilised gauze wet with the same solution being in contact with the skin and covered with dry sterilised cotton wool and a bandage. When $I$ saw the patient on the next day I found that the skin of the entire axilla, of the subaxillary region, and of a portion of the adjacent lateral anterior and posterior regions of the thorax was of a scarlet colour and dotted all over with small vesicles containing pus. The girl complained of a sensation of smarting and severe itching. The lesion was very similar to a burn of the first degree. The affected region corresponded exactly to the area which had been in contact with the corrosive sublimate even for a brief period. The same lesion also existed on part of the anterior and posterior aspect of the axillary folds where gauze sterilised and wetted with the solution of corrosive sublimate had been applied. The girl told me that several years ago she had suffered in the same way from the use of a solution of mercuric chloride employed by a medical man and that he was surprised at the effect produced. Three days afterwards the abscess was almost healed but over the whole of the affected surface there was subsequent exadation of a serous fluid mixed with a very small quantity of pus. From the first appearance of the lesion I made no further nse of sublimate or any other disinfectant. I only washed the parts every day with sterilised water and cotton wool and then covered them with sterilised gauze and cotton wool. Powdered bismuth subnitrate was also sprinkled upon the skin and sterilised gauze and cotton wool were applied. The lesion disappeared in a few days.

New York.

\section{A dutirur \\ or}

\section{HOSPITAL PRACTICE, BRITISH AND FOREIGN.}

Nulla autem est alia pro certo noscendi via, nisi quamplurimas et morborum et dissectionum historias, tum aliorum tum proprias collectas habere, et inter se comparare.-MoRGAGNT De Sed. et Caus. Morb., lib. iv., Proomium.

\section{RADCLIFFE INFIRMARY, OXFORD.}

A CASE OF MUSCULAR ATROPHY, WITH "STOCKING-GLOVE" ANASTHESIA, SHOWING GRADUAL IMPROVEMENT.

(Under the care of Dr. W. Collier.)

For the report of the case we are indebted to Mr. H. C. Lecky, late house physician.

The patient, a man, aged 20 years, was admitted to the Radcliffe Infirmary, Oxford, under the care of Dr. W. Collier, on Nov. 18th, 1905. He was sent in for paralysis of the arms and legs of about 12 months' duration. When first seen he was a healthy-looking man, well nourished, and not at all thin or emaciated. He was lying flat in bed and was quite unable to raise himself. He could not even get his shoulders off the bed. He could with difficulty roll himself over. When the upper part of the body was stripped no obvious wasting of any group of muscles was detected. The shoulders could be shrugged. In certain positions the arms could be voluntarily bent but he could not extend them again. The fingers could be moved slightly. The patient could not grip at all with either hand. The thenar and hypothenar eminences seemed to be a little flat. The interossei were not appreciably wasted. The legs at first sight did not show any obvious and marked wasting, although the thighs looked somewhat thin. The thighs could be weakly flexed on the abdomen but there was very great difficulty in extending them again. At the same time it was observed that the patient could exert, to a certain extent, more strength the more he was opposed. There was fairly good movement of the ankles and toes. The chest expanded well. The abdominal muscles seemed to be weak and the abdomen did not move well on inspiration. Sensation was tested with cotton-wool, a pin, and hot and cold water in test-tubes, with the following result. Tactile sensation in the arms was perfect, but painful stimuli and hot and cold stimuli were not felt at all below a circular line drawn round the shoulder-joint. Tactile, painful, hot, and cold sensations were all completely absent below a circular line drawn immediately above the patella. Sensation over the rest of the legs and the whole of the body was perfect. As regards the reflexes, the elbow, wrist, knee, and tendo Achillis jerks were all absent. The cremasteric reflex was brisk on both sides. The abdominal reflexes were absent. Plantar stimulation gave no definite response on either side. No attempt was made at patellar or ankle clonus. There was no evidence of affection of any of the cranial nerves. There was no nystagmus, although the eyes did not fix well on looking to the extreme right. The fields of vision and the fundi were normal. The pupils were equal and active. The small muscles of the face acted well. There was no wasting of the tongue or difficulty in swallowing. The palate acted normally. The temperature, pulse, and respiration were normal. Arterio-sclerosis was not present. There were no physical signs of disease in the chest or abdomen. The testicles were extremely small and rather hard but apparently the normal sensibility was retained. The patient stated positively that they had been at one time much larger and had only become smaller during his illness. The penis was not proportionately small and it was stated that erection was possible. There was no evidence anywhere on the body either of acquired or congenital syphilis. The mental condition was perfectly clear and the patient could give a 